\title{
Release Modification of Indomethacin Controlled Release Press Coated Tablets
}

\author{
Muhammad Rashedul Islam ${ }^{1}$, Md. Elias-al-Mamun ${ }^{1}$ and Md. Mizanur Rahman Moghal ${ }^{2}$ \\ ${ }^{1}$ Department of Pharmaceutical Technology, Faculty of Pharmacy, University of Dhaka, Dhaka-1000, Bangladesh \\ ${ }^{2}$ Department of Pharmacy, Mawlana Basani Science and Technology University, Tangail-1902, Bangladesh
}

Received: June 28, 2016; Accepted: July 24, 2016; Published (Web): July 31, 2016

\begin{abstract}
The study was carried out to evaluate the release modification of indomethacin press coated tablets through different polymers. Several batches of press coated tablets were prepared with indomethacin and Avicel PH 102. The core tablet was compression coated with minimal compression pressure. Formulation IX was modified by incorporating PEG 6000, sodium chloride and sodium lauryl sulphate (SLS). In vitro dissolution studies of the formulations of different excipients were done at $\mathrm{pH} 7.2$ in phosphate buffer using USP apparatus 2 (paddle method) at $50 \mathrm{rpm}$ and $37 \pm 0.5{ }^{\circ} \mathrm{C}$ temperature. The drug release data was treated in different mathematical fashion to identify the kinetic behaviour. It was found that, drug release which was inversely proportional to the amount of xanthan gum in the coating formulations was significantly changed by the polymers used in the study. Incorporation of SLS caused the drug to be released in near zero order fashion. Drug release was found to follow Higuchi mechanism for all the formulations. The study reveals that the polymers used may be a significant factor for the discrepancy in release rate of indomethacin.
\end{abstract}

Key words: Indomethacin, Sodium chloride, Sodium lauryl sulphate, PEG-6000, Press coating technology.

\section{Introduction}

The past several decades have seen the development of many controlled-release preparations featuring constant release rates to maintain drug concentrations in the human body, regardless of the patient's physiological condition (Khadabadi et al., 2013). The press coating technique is a simple and unique technology used to provide tablets with a programmable lag phase, followed by a fast, or ratecontrolled, drug release after administration. The technique offers many advantages, and no special coating solvent or coating equipment is required for manufacturing this type of tablet (Lin and Kawashima, 2012). Methods that release drug with zero order kinetics (a time-independent rate) for an extended time period is usually considered optimal (Andrews et al., 2008; Yoshihiro et al., 2009).
Indomethacin [1-(4-chlorobenzoyl)-5-methoxy-2methyl- $1 \mathrm{H}$-indole-3-acetic acid] is a non-steroidal antiinflammatory indole derivative used to treat acute and chronic rheumatoid arthritis and osteoarthritis was used previously as model drug to develop pulsatile release system (Purpora et al., 2013; Islam et al., 2015). This study focused on the modification of drug release through these press coated tablets by the use of various release modifiers. So, excipients like sodium chloride, sodium lauryl sulphate (SLS) and polyethylene glycol (PEG-6000) were included in the formulations and their effect on the indomethacin release from press coated tablets was studied in order to achieve therapeutically effective levels. 


\section{Materials and Methods}

Drugs and chemicals: Indomethacin was purchased from Nipa pharmaceuticals Limited. Xanthan gum was collected from sole agent Orchid Chemicals (India). microcrystalline cellulose (Avicel PH 102), hydroxy propyl methyl cellulose, lactose, polyethylene glycol (PEG-6000), sodium lauryl sulphate (SLS), sodium chloride and magnesium stearate were kind gifts from Nipa Pharmaceuticals Ltd. and Eskayef Pharmaceuticals Ltd, Bangladesh. Potassium dihydrogen phosphate of Merck (Germany), $\mathrm{HCl}$ (37\%) of Merck (Germany) and purified water from our research laboratory were used. Among the instruments, vernier caliper of Erweka (Germany), Shimadzu UV Spectrophotometer (Japan), hardness tester and dissolution tester were from Erweka (Germany), Pharmatest disintegration tester (Germany), mini drum blender of Cadmach Machinery (India), friability tester of Logan (USA), Hanna pH meter (Portugal), stainless steel sieve (Bangladesh) and Manesty 16 station compression machine (England) were used.

Preparation of matrix tablet: The core was made of the suitable mixture of powder blends of indomethacin, microcrystalline cellulose (Avicel $\mathrm{PH}$ 102), lactose and xanthan gum following the procedure described previously (Islam et al., 2015) (Table 1). All of the above ingredients were dry blended for 5 minutes followed by the addition of magnesium stearate. The mixture was then further blended for 30 minutes. Cores were compressed with minimum compression force using round, flat punches $(7.5 \mathrm{~mm}$ diameter $)$. Formulation IX was designed where the ratio of lactose to xanthan gum was kept at 85:15. Three more formulations (IX-NaCl, IX-SLS, IX-PEG) were prepared where a fixed amount $(5.7 \mathrm{mg} / \mathrm{tab})$ of sodium chloride $(\mathrm{NaCl})$, SLS and PEG 6000 were added to the compression coating material replacing the equivalent amount of xanthan gum. Now drug release profile was evaluated as a function of xanthan load and different excipients present in the compression coat.

Preparation of dissolution media: A) For preparation of $0.1 \mathrm{~N} \mathrm{HCl}: 11 \mathrm{ml}$ of $35 \%(\mathrm{w} / \mathrm{v}) \mathrm{HCl}$ was taken in a $1000 \mathrm{ml}$ volumetric flask and diluted up to the mark with distilled water. The concentration of this solution was $0.1 \mathrm{~N}$. B) For preparation of phosphate buffer ( $\mathrm{pH}$ 7.2): $13.60 \mathrm{gm}$ of potassium dihydrogen phosphate was taken in to a $1000 \mathrm{ml}$ volumetric flask, dissolved in and diluted up to the mark with distilled water. The concentration of the solution was $0.1 \mathrm{M}$. Then $500 \mathrm{ml}$ of this solution was taken in to an another $1000 \mathrm{ml}$ volumetric flask, $36 \mathrm{ml} 0.1 \mathrm{M}$ sodium hydroxide was added and finally the volume was made up to $1000 \mathrm{ml}$ with distilled water.

In vitro dissolution study: The dissolution of the prepared matrix tablets was studied by using Erweka dissolution tester (Paddle method), with a rotation of 50 rpm at $37^{0} \pm 0.5^{\circ} \mathrm{C}$ placing 1-liter dissolution media in each vessel. Three tablets from each batch were taken into three vessels. It means the experiment was carried out in triplicate and each time we ran two batches. After each specified time intervals $5 \mathrm{ml}$ of the dissolution media was withdrawn from each vessel for assay of drug content and was replaced by a fresh portion of medium of same volume. The collected sample was then filtered through Whattman no. 41 filter paper. Then $1 \mathrm{ml}$ filtrate was taken into a $50-\mathrm{ml}$ volumetric flask and diluted up to the mark with dissolution media. The absorbance of the samples was measured at $267 \mathrm{~nm}$ by using Shimadzu UV spectrophotometer. Now the percent release of drug was calculated from the measured absorbance. The dissolution was performed using phosphate buffer ( $\mathrm{pH} 7.2$ ).

Release kinetics: The suitability of several equations that are reported in the literature to identify the mechanisms for the release of indomethacin was tested with respect to the release data. The data were evaluated according to the Higuchi model (Higuchi T., 1963; Rajesh et al., 2009).

$$
\mathrm{M}_{\mathrm{t}}=\mathrm{M}_{0}+\mathrm{K}_{\mathrm{H}} \mathrm{t}^{0.5}
$$

Where $\mathrm{M}_{\mathrm{t}}$ is the amount of drug dissolved in time $t$, $\mathrm{M}_{0}$ is the initial amount of drug, $\mathrm{K}_{0}$ is the zero-order release constant, $\mathrm{K}_{\mathrm{H}}$ is the Higuchi rate constant, $\mathrm{K}$ is a release constant, and $\mathrm{n}$ is the release exponent that characterizes the mechanism of drug release.

Statistical analysis: Among the model independent approaches, one-way analysis of variance (ANOVA) (performed at 5\% significance level using SPSS Version 16.0) were used to compare the difference of dissolution profiles of the test matrix tablets. 


\section{Results and Discussion}

In the present experiment, Carr's compressibility index and Hausner ratio of all the formulations of indomethacin press coated tablets have been calculated and prepared (Table 2). It was found that all the individual excipients and the mixture had the flow parameters within the range allowing desirable flow property.
Excipients have multifarious effect on drug release profile from the dosage form. In the present study $\mathrm{NaCl}$, SLS and PEG-6000 were incorporated into the compression coat to assess the effect of these excipients on drug release. Significant difference was found in release profile when different polymers were added into the system. The formulations containing different polymers were compared with formulation-IX (formulation that released $46 \%$ indomethacin after 12 hrs).

Table 1. Formulation of indomethacin press coated tablets based on different polymers.

\begin{tabular}{lcccc}
\hline Ingredient & IX & IX-NaCl & IX-SLS & IX-PEG \\
\hline Core & & & & \\
\hline Indomethacin & $75 \mathrm{mg}$ & $75 \mathrm{mg}$ & $75 \mathrm{mg}$ & $75 \mathrm{mg}$ \\
Avicel PH102 & $75 \mathrm{mg}$ & $75 \mathrm{mg}$ & $75 \mathrm{mg}$ & $75 \mathrm{mg}$ \\
Magnesium stearate & $1.5 \mathrm{mg}$ & $1.5 \mathrm{mg}$ & $1.5 \mathrm{mg}$ & $1.5 \mathrm{mg}$ \\
Coat & & & & \\
\hline Lactose & $483 \mathrm{mg}$ & $483 \mathrm{mg}$ & $483 \mathrm{mg}$ & $483 \mathrm{mg}$ \\
Xanthan gum & $85.5 \mathrm{mg}$ & $79.8 \mathrm{mg}$ & $79.8 \mathrm{mg}$ & $79.8 \mathrm{mg}$ \\
Magnesium stearate & $1.5 \mathrm{mg}$ & $1.5 \mathrm{mg}$ & $1.5 \mathrm{mg}$ & $1.5 \mathrm{mg}$ \\
NaCl & - & $5.7 \mathrm{mg}$ & - & - \\
SLS & - & - & $5.7 \mathrm{mg}$ & - \\
PEG-6000 & - & - & - & $5.7 \mathrm{mg}$ \\
\hline
\end{tabular}

Table 2. Flow properties of indomethacin press coated tablets based on different polymers.

\begin{tabular}{lcc}
\hline Ingredients / Mixtures & Carr's compressibility & Hausner ratio \\
\hline Formulation IX & 13.58 & 1.23 \\
Formulation IX-NaCl & 14.08 & 1.21 \\
Formulation IX-SLS & 13.74 & 1.20 \\
Formulation IX-PEG & 14.27 & 1.25 \\
\hline
\end{tabular}

Release profiles of indomethacin from $\mathrm{NaCl}$ based press coated tablet preparation: The release of indomethacin from $\mathrm{NaCl}$ loaded press coated tablets was shown in Figure 1. $\mathrm{NaCl}$ modifies the release rate of drug by preferential solubulity thereby creating pores and channels into the matrix through which drug can be released from the core. Utilization of $\mathrm{NaCl}$ in modulating drug release has previously been reported (Contreras et al., 2010). Formulation IX-NaCl was designed to evaluate the effect of $\mathrm{NaCl}$ on drug release from central core matrix tablet. An amount corresponding to $5.7 \mathrm{mg}$ of $\mathrm{NaCl}$ was included in the compression coating formulation by replacing equivalent amount of xanthan gum. Formulation IX$\mathrm{NaCl}$ was compared with formulation IX-2 in terms of release profile. It was found that, release pattern of indomethacin from IX-NaCl was higher than that found with formulation IX in both rate and extent of indomethacin release. Approximately $50 \%$ of indomethacin was released from $\mathrm{IX}-\mathrm{NaCl}$ formulation after 12 hours. A lag phase of 1-1.5 hours was observed which might be due to the attrition of the compression 
coat. $\mathrm{NaCl}$ present in the compression coat dissolves rapidly as the tablet is immersed into the dissolution fluid thus creating many pores and channels. Dissolution fluid permeated into the tablet through these channels and reached the central core. The surface drug present in the central core was then dissolved in the aqueous micro-environment and ultimately leached out of the tablet network and the process continued. Evaluation of the release data by Higuchi model presented high value of correlation coefficients which indicates that drug dissolution was carried out with the help of matrix diffusion mechanism as presented in figure 4. The Higuchi release rate was $4.58 \% /$ time $^{-1 / 2}$.

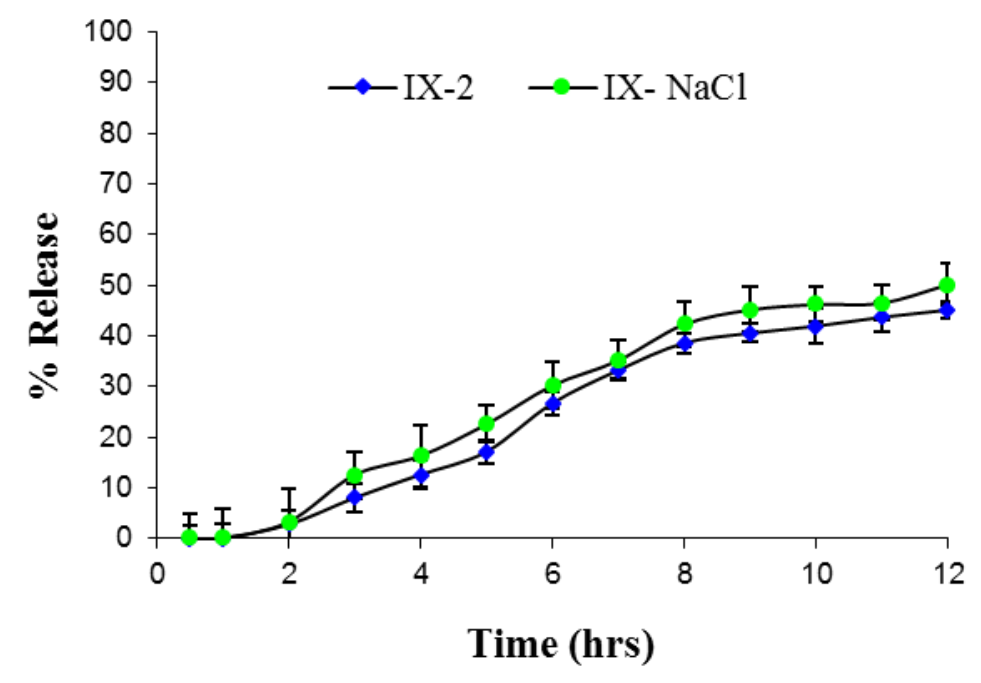

Figure 1. Release profile of indomethacin from $\mathrm{NaCl}$ based press coated tablets.

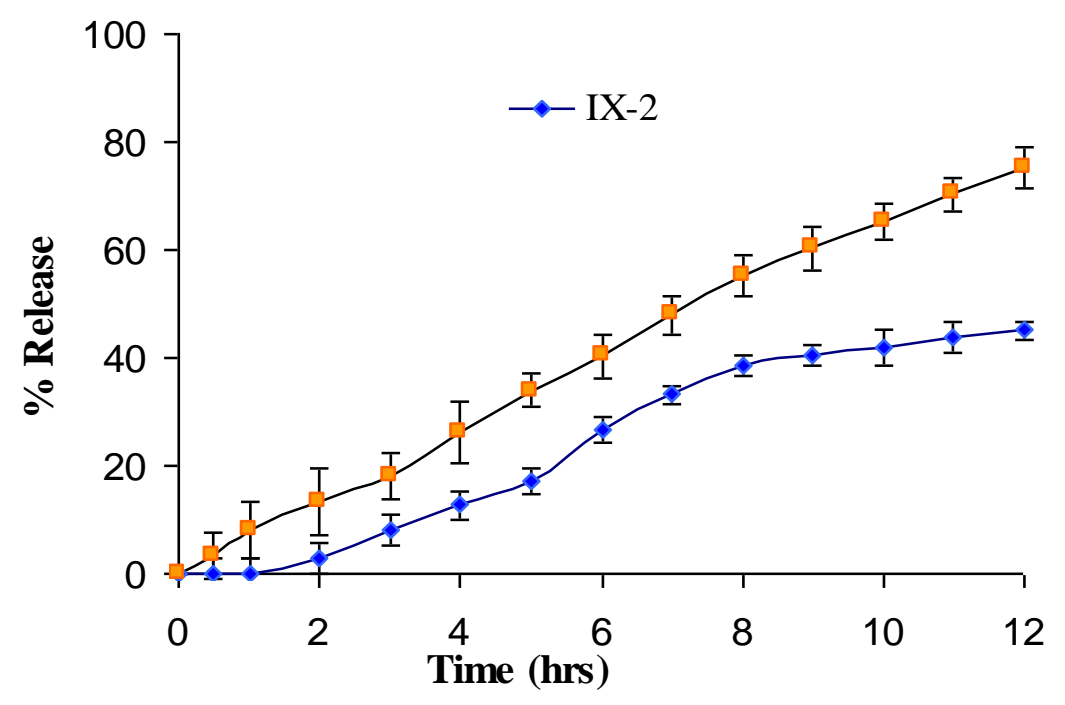

Figure 2. Release profile of indomethacin from SLS based press coated tablets.

Release profiles of indomethacin from SLS based press coated tablet preparation: Effect of SLS on drug release from press coated tablets was presented in figure 2. The rate, extent and pattern of indomethacin release were significantly different when SLS was incorporated into the compression coat of the press 
coated tablets. Effect of SLS on drug release has been reported previously (Nalluri et al., 2012). SLS is a long chain sulfated ester of lauric acid which is used as surface active agent (Emeje, et al., 2007) When SLS was incorporated into the formulation IX-SLS drug release showed a very close adherence to zero order profile. Existence of lag phase was not evident from this formulation. About $82 \%$ of indomethacin was released after 12 hours of dissoution period which was considerably higher than that from IX formulation. After 6 hours of dissolution, approximately $40 \%$ of active was released from this formulation which is almost double of that from IX. When the release pattern was evaluated with the help of Higuchi kinetics, again a higher value of correlation coefficient was found. The release rate was $6.18 \% /$ time $^{-1 / 2}$. SLS, being an ester with sulphate moeity, permits the inclusion of water into the tablet through the micropores present in the tablet surface from the beginning of the dissolution process. As a result water enters into the tablet and exerts its hydrodynamic pressure within the tablet structure. This ultimately loosens the tablet integrity and permits more dissolution medium to reach the central core matrix. Consequently, drug release was elevated. The absence of lag phase can be attributed to the loss of tablet integrity by surface active property of SLS.

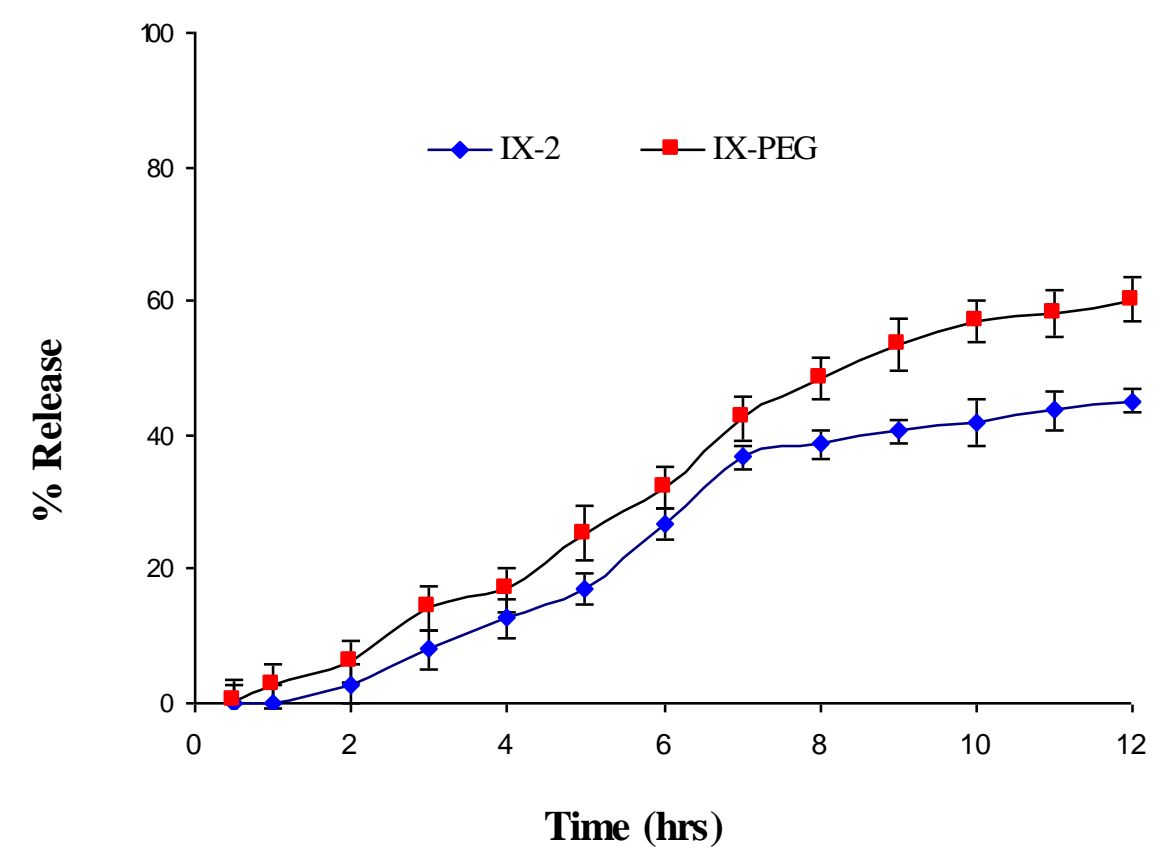

Figure 3. Release profile of indomethacin from PEG-6000 based press coated tablets.

Release profiles of indomethacin from PEG-6000 based press coated tablet preparation: The effect of incorporation of PEG 6000 on indomethacin release is presented in figure 3 . The rate and extent of drug release from formulation IX-PEG was significantly different from IX.

The incorporation of drugs into a water soluble carrier has frequently been reported, to improve drug dissolution rate and bioavailability (Yeole et al., 2006).
On contact with water, particles of PEG swell to form a gel like matrices prior to dissolution. At low concentration aqueous solutions of PEG exhibit newtonian behaviour, i.e. rate of distortion being proportional to the stress applied. In this circumstance, the stress is applied from the perturbation of the dissolution medium. Release of indomethacin from PEG loaded press coated tablets was higher from that of IX. About $65 \%$ of indomethacin was released from 
PEG loaded tablets. The rate was also higher than IX. Lag phase was present in the dissolution pattern. A number of factors can be held responsible for increased dissolution of indomethacin. Higher release of PEG can be attributed the higher solubility of PEG in aqueous medium. PEGs, being highly soluble in water, acts as channeling agent and is preferentially liberated from the

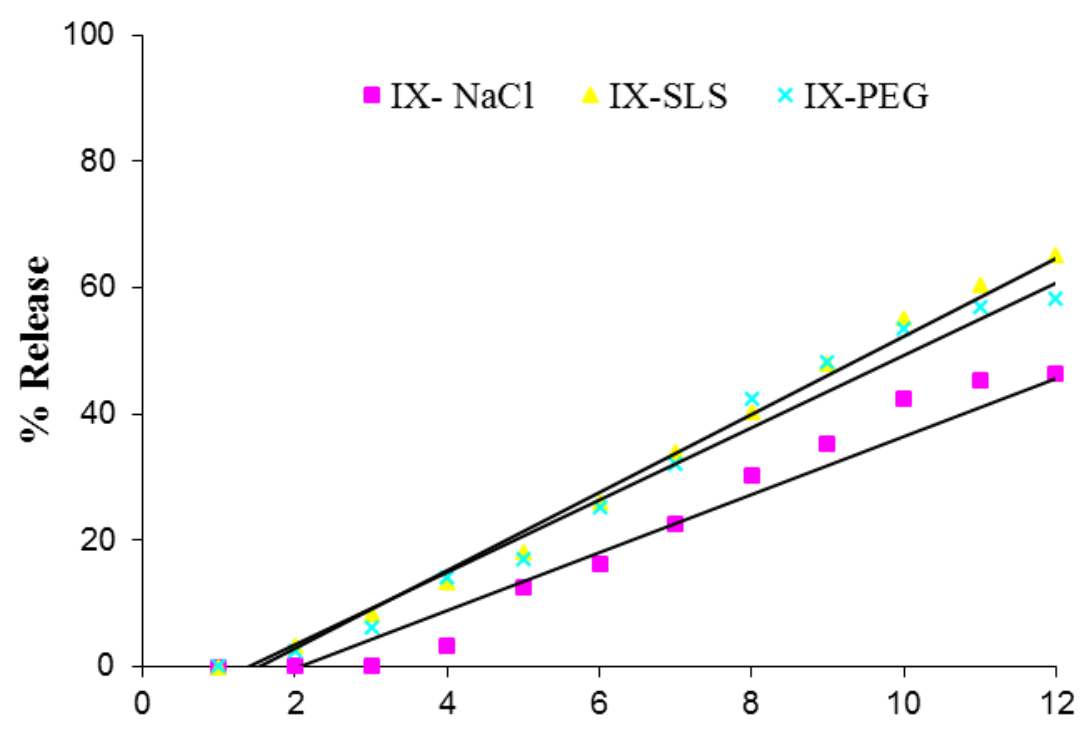

Time (hrs)

Figure 4. Effect of different polymers on Higuchi Release of indomethacin press coated tablets.

matrix surface, causing the formation of pores and cracks and thereby facilitating drug release. Again for an inert matrix system, the porosity of the matrix is the void space plus the space occupied by soluble materials. Therefore an incorporation of soluble component in the formulation means higher porosity, resulting in faster drug release. PEG-6000, due to their possession of water solubility and swelling property as mentioned earlier induced the formation of cracks on matrix surface, which effectively created new surface dimension inside of matrix system leading to persistent enhanced release of indomethacin throughout the 12 hours of dissolution period. Although, the tablets were prepared by dry mixing followed by direct compression of the compression coat, some fusion might occur due to the heat that was generated during the compression stage which might have helped in the formation of solid solution of indomethacin in PEG 6000. Such cause might have induced the reduction of particle size of the indomethacin and enhanced drug release. Additionally, it has been reported that, PEGs may reduce the tendency of drug particles to form agglomerates or aggregates due to the physical separation of particles by the carrier and thereby increasing the effective surface area of drug particles exposed to the dissolution medium. Again, the ability of PEG to increase the equilibrium aqueous solubility of drugs may also predisposed as the governing factor in elevating drug release from press-coated tablets (Meshukul et al., 2010).

\section{Conclusion}

The present study allowed to assess, the feasibility of fabrication of press-coating controlled release tablets loaded with indomethacin and the release profile of drug either alone or in combination with different excipients. The experiment indicates that, it is possible to design controlled release press coated tablets that is able to deliver drug at the desired rate. The rate and extent of drug release can be modulated accordingly by varying the type and amount of rate-modifiers. 


\section{Acknowledgements}

The authors would like to acknowledge the support received from the Nipa Pharmaceuticals Ltd. and Eskayef Bangladesh Ltd.

\section{References}

Andrews, G.P., Jones, D.S., Diak O.A,. McCoy C.P., Watts O.K. and McGinity, J.W. 2008. The manufacture and characterisation of hot-melt extruded enteric tablets, Eur. J. Pharm. Biopharm. 69, 264-273.

Contreras, L., Megoza, L.M., Villabos, R. and Caraballo, I. 2010. Study of the critical points of experimental HPMC-NaCMC hydrophilic matrices. Int. J. Pharm. 386, 52-60.

Emeje, M.O., Isimi, C.Y., Kunle, O.O. and Ofoefule, S.I. 2007. Effect of polyethylene glycol and sodium lauryl sulphate on the compaction characteristics of eudragit and drug release from its matrix.J. App. Sci. 7, 2598-2603

Purpora, R., Massad, W., Ferrari, G., Reynoso, E., Criado, S., Miskosi, S., Pajares, A. and Garcia, N.A. 2013. The NSAIDs indomethacin and diflunisal as scavengers of photogenerated reactive oxygen species. Photochem. Photobiol. 89, 1463-1470.

Rajesh, K.S., Venkataraju, M.P. and Gowda, D.V. 2009. Effect of hydrophilic natural gums in formulation of oral-controlled release matrix tablets of propranolol hydrochloride. Pak. J. Pharm. Sci. 22, 211-219.

Higuchi T. 1963. Mchanism of sustained-action medication. Theoretical analysis of rate of release of solid drugs dispersed in solid matrices. J. Pharm. Sci. 52, 11451149.

Khadabadi, S.S., Nahid, H.C., Farhan, M.K. and Akeel, A.T. 2013. Formulation and evaluation of press coated tablet ketoprofen - a chronotherapeutic approach. Int. J. Pharm. Pharm. Sci. 5, 733-740.

Lin, S.Y. and Kawashima, Y. 2012. Current status and approaches to developing press-coated chronodelivery drug systems. J. Control. Rel. 157, 331-353.

Meshakul, A., Yodklum, K., Mahadlek, J. and Phaechamud, T. 2010. Characterization of indomethacin release from polyethylene glycol tablet fabricated with mold technique. Ind. J. Pharm. Sci. 72, 92-100.

Nalluri, B.N., Vidyasagar, S. and Maheswari, K.M. 2012. Effect of excipients on oxcarbazepine release from modified release matrix tablets. J. App. Pharm. Sci. 2, 150-158.

Yeole, P.G., Galgatte, U.C., Babla, I.B. and Nakhat, P.D. 2006. Design and evaluation of xanthan gum based sustained release matrix tablets of diclofenac sodium. Ind. J. Pharm. Sci. 68, 185-189.

Yoshihiro, T., Hioroyuki, O. and Makoto, O. 2009. Noninvasive and rapid analysis for observation of internal structure of press-coated tablet using X-ray computed tomography. Drug Dev. Ind. Pharm. 35, 678-682. 